\title{
Subjective and objective effects of coffee consumption - caffeine or expectations?
}

\author{
Zs Dömötör ${ }^{1}$, R Szemerszky², F Köteles ${ }^{2}$ \\ ${ }^{1}$ Department of Physiology and Neurobiology, Eötvös Loránd University, Budapest, Hungary \\ ${ }^{2}$ Institute for Health Promotion and Sport Sciences, Eötvös Loránd University, Budapest, Hungary
}

Received: December 5, 2012

Accepted after revision: May 10, 2013

\begin{abstract}
Impact of $5 \mathrm{mg} / \mathrm{kg}$ caffeine, chance of receiving caffeine (stimulus expectancies), and expectations of effects of caffeine (response expectancies) on objective (heart rate (HR), systolic/diastolic blood pressure (SBP/DBP), measures of heart rate variability (HRV), and reaction time (RT)) and subjective variables were investigated in a double-blind, placebo-controlled experiment with a no-treatment group. Participants were 107 undergraduate university students (mean age $22.3 \pm 3.96$ years). Consumption of $5 \mathrm{mg} / \mathrm{kg}$ caffeine had an impact on participants' SBP, standard deviation of normal heartbeat intervals, HR (decrease), and subjective experience 40 minutes later even after controlling for respective baseline values, stimulus and response expectancies, and habitual caffeine consumption. No effects on DBP, high frequency component of HRV, the ratio of low- and high-frequency, and RT were found. Beyond actual caffeine intake, response expectancy score was also a determinant of subjective experience which refers to a placebo component in the total effect. Actual autonomic (SBP, HR) changes and somatosensory amplification tendency, however, had no significant impact on subjective experience. Placebo reaction plays a role in the subjective changes caused by caffeine consumption but it has no impact on objective variables. Conditional vs deceptive administration of caffeine (i.e. stimulus expectancies) had no impact on any assessed variable.
\end{abstract}

Keywords: double-blind versus deceptive administration, caffeine, placebo, blood pressure, heart rate, heart rate variability, expectations

Caffeine is one of the most widely consumed behaviorally active substances in the world, its physiological and psychological effects (e.g. increasing alertness, enhancing vigilance, reducing fatigue, elevating blood pressure) are widely known and utilized (1, 28, 38, 39). Although caffeine acts in several different ways, its most important biological effect is inhibition of adenosin receptors in the brain $(1,32)$. Pharmacological effects of caffeine are usually well observable in animal models (39). In the case of humans, however, the phenomenon is more complicated: anticipation of caffeine intake and expectations about the effects of caffeine may also play a role in the final response pattern $(7,8,13,25)$. Expectations or expectancies are categorized into three groups (45): (1) stimulus expectancies refer to one's belief that he is about to ingest an active substance (in the case of caffeine, these expectancies are triggered, e.g. by taste and smell of coffee); (2) response expectancies are expectations about the responses evoked by the drug taken (e.g. the knowledge that caffeine

Corresponding author: F. Köteles

Institute for Health Promotion and Sport Sciences, Eötvös Loránd University

Bogdánfy Ödön u. 10, H-1117, Budapest, Hungary

Phone: +3612090619; E-mail: koteles.ferenc@ppk.elte.hu 
elevates blood pressure and improves awareness); and (3) expectancies about the consequences of the consumption of the given drug (e.g. social consequences of regularly having a coffee with colleagues). According to studies on alcohol, caffeine, and other substances, expectancies often moderate pharmacological effects of psychoactive drugs and can even mimic certain pharmacological effects in the absence of any active substance (i.e. when participants receive placebo (45)).

In addition to sensory stimuli, verbal information has also an impact on stimulus expectancies. In the case of double-blind RCT, participants are informed that they will receive an active substance or placebo, and they are also aware of the likelihood of receiving the active substance (e.g. 0.5 or 0.7 ) - this is called conditional (or double-blind) administration $(17,18)$. From methodological point of view, this way of administration as opposed to deceptive administration when patients firmly believe that they receive the active substance (likelihood $=1.0$ ) may lead to underestimation of the magnitude of the placebo effect. Deceptive administration may have a higher external validity, however, it cannot be used in RCTs for ethical reasons.

Caffeine may serve as an appropriate model to investigate this problem as it is legal, widely used, and there exists a placebo (i.e. decaffeinated coffee) that is not easily distinguishable from the active preparation. In an early study (18), individuals receiving caffeine placebo with deceptive information showed higher HR and subjective tension than the conditional information group (no differences in blood pressure were reported). In a second study (17) using a more sophisticated design including groups that received caffeine or placebo with deceptive, conditional, or negative (i.e. participants were told that the drink contained no caffeine) information and measurements 15,30 , and 45 minutes following the administration, effects of information and information-caffeine interactions were found. For example, deceptive information had an impact on participants' alertness 15 minutes after ingestion in both the caffeine and placebo groups, whereas pharmacological effect of caffeine was measurable in the next period. Difference between the effects of deceptive and doubleblind information was found in the case of DB, while SBP was only influenced by the actual caffeine intake. In summary, the information given to participants about the likelihood of receiving the active substance (stimulus expectancy) had an impact on certain variables in both the placebo and the caffeine groups. Interestingly, in other studies with placebo-groups only $(46,47)$ or with placebo and caffeine groups $(24)$, no such differences were found.

In studies that operated with deceptive administration only, mixed and often contradictory results were reported in various cognitive tasks. A synergistic caffeine-information effect was reported in vigilance and psychomotor tasks (8-10), while no or minimal interaction was found in other experiments (7). The manipulation of response expectancies (beliefs about the effects of caffeine) also changed participants' reactions (29), although sometimes in the opposite direction (i.e. stimulant instruction had a negative impact on reaction time) (14).

\footnotetext{
Abbreviations

$\mathrm{BP}=$ blood pressure

$\mathrm{DBP}=$ diastolic blood pressure

$\mathrm{SBP}=$ systolic blood pressure

$\mathrm{HR}=$ heart rate

$\mathrm{HRV}=$ heart rate variability

$\mathrm{HF}=$ high frequency components of $\operatorname{HRV}(0.15-0.4 \mathrm{~Hz})$

$\mathrm{LF}=$ low frequency components of $\operatorname{HRV}(0.04-0.15 \mathrm{~Hz})$

Acta Physiologica Hungarica 102, 2015
}

\author{
$\mathrm{LF} / \mathrm{HF}=$ the ratio of low- and high-frequency power \\ RCTs = randomized controlled trials \\ $\mathrm{SDNN}=$ standard deviation of normal to normal R-R \\ intervals \\ SRQ $=$ self-reported questionnare \\ SSAS = Somatosensory Amplification Scale
}


Autonomic variables (HR, SBP, DBP) as opposed to subjective variables have usually not been influenced by verbal information about the caffeine content of the drink $(12,21,36,42)$.

In addition to information given to participants, lack of appropriate control group represents a further methodological problem in many studies investigating the placebo effect. Changes in placebo groups are attributable to many factors beyond the genuine placeboreaction (e.g. natural fluctuations of the given state or symptom, regression to the mean, etc.), thus a non-treated control group (natural history group) is needed to exclude these disturbing factors (4). In many studies investigating the effects of placebo caffeine, no natural history group was included (usually the so-called balanced placebo design was used), and no research has been published to date that studied these effects on groups receiving placebo caffeine or real caffeine with deceptive or conditional information and with a non-treated control group.

The present study aimed to fill this gap and to study the placebo caffeine phenomenon in a complex way. It was hypothesized that actual intake of caffeine and/or higher stimulus expectancies would increase participants' BP, HR, HRV-HF, HRV-LF/HF and reaction time, and would lead to more self-reported caffeine-related symptoms. Moreover, we have hypothesized that peripheral autonomic variables, actual caffeine intake, stimulus and response expectancies, and proneness to amplify subjective symptoms (somatosensory amplification) would have an impact on perceived effects of caffeine.

\section{Materials and Methods}

\section{Participants}

107 undergraduate university students (mean age $22.3 \pm 3.96$ years; $39.3 \%$ male) volunteered to participate in the experiment. Students received no reward for their participation. Individuals with known cardiovascular problems or caffeine sensitivity were excluded from the study.

\section{Objective measurements}

Cardiovascular data (HR, HRV, BP) were recorded. Electrodes were placed to the distal ends of the collarbones and to the anterior superior iliac spines. HR and HRV (SDNN, HF, LF/HF) values were calculated from one-minute intervals of resting sessions, SBP and DBP were measured at the end of the resting sessions. Reaction time measurement was carried out using the PsychLabWin v1.1 software. The measurement consisted of 90 trials, it took approximately 5-7 minutes to complete.

\section{Questionnaires}

Habitual caffeine consumption were assessed using a single question ("How often do you drink a coffee?") to be rated on a 5-pont Likert-scale (never/sometimes/several times a week/ once a day/several times a day).

Expectancies about the effects of coffee (response expectancies) and actually experienced effects were measured using the SRQ-scale developed by Rush $(15,34)$. The SRQ assesses the existence of sixteen psychic (e.g. alertness, concentration) and somatic (e.g. palpitation, headache) caffeine-related symptoms on a 4-point Likert-scale (not at all/a bit/to great extent/extremely). In the case of $\mathrm{T} 1$ (baseline) and $\mathrm{T} 2$ measurements, participants were asked to rate the actual severity of the symptoms and conditions, while they had to mark expected severity of symptoms in the expectancy measurement. Internal consistency (Cronbach's alpha coefficients) of the scale was between 0.72 and 0.80 . 
Proneness to amplify perceived symptoms was assessed by the 10-item SSAS (3). Somatosensory amplification refers to the tendency to experience somatic sensations as intense, noxious, and disturbing. The Hungarian version proved to be psychometrically sound in previous studies (20), its Cronbach's $\alpha$ coefficient was rather low (0.63) in the present study.

\section{Procedure}

The whole procedure was approved by the Ethical Committee of the Faculty of Education and Psychology, Eötvös Loránd University, Hungary. The procedure met the requirements of the World Medical Association Declaration of Helsinki and the Decree No 23/2002 (V. 09.) EüM on Medical Trials Made on Human Subjects. Participants were asked to avoid caffeine intake 12 hours before the experiment. Upon arrival, participants received detailed information about the experimental procedure and signed the informed consent form. Following the placement of ECG-electrodes and the completion of T1 (baseline) measurements (personal data, actual and expected SRQ, SSAS, cardiovascular data, and reaction time), they were arranged in five groups in a quasi-random manner to maintain gender ratio. One group (natural history group, $N=22$ ) had to drink a cup of room-temperature (approx. $22-23{ }^{\circ} \mathrm{C}$ ) water with the instruction that it contains no caffeine (stimulus expectancy in this group was 0.0 ). The remaining four groups drunk a cup of decaffeinated warm (approx. $40-45{ }^{\circ} \mathrm{C}$ ) coffee containing $5 \mathrm{mg} / \mathrm{kg}$ caffeine or no caffeine. Two groups (conditional caffeine group, $N$ $=20$ and conditional placebo group, $N=18$ ) were told that they would drink caffeinated or decaffeinated coffee with equal chance (stimulus expectancy $=0.5$ ) and they received caffeinated or caffeine-free coffee, respectively. The last two groups (caffeine group, $N=25$ and deceived placebo group, $N=22$ ) were informed that they would receive a cup of strong coffee (stimulus expectancy $=1.0$ ) but they received caffeinated or decaffeinated coffee, respectively. Drinks were serviced by an assistant in a separate room thus the experimenter was not aware of the participants' group affiliation in the remaining part of the experiment. Following the ingestion of the drink, participants were asked to relax for 35 minutes, then they had to rate the perceived strength of the coffee they consumed on a 5-point Likert-scale. Post-experimental analysis revealed that nobody in the deceived caffeine group or in the caffeine group thought that he or she received decaffeinated coffee, thus the deception was considered successful. Finally, T2 data (actual SRQ, cardiovascular data, and reaction time) were recorded, and participants were informed about their group affiliation.

\section{Statistical analysis}

Descriptive statistics of the assessed variables were presented in Table I. As we intended to investigate the contribution of multiple factors (e.g. respective baseline value, habitual caffeine consumption, various forms of expectancies, etc.) to the results at T2 and data were appropriate for parametric analysis, multiple linear regression analysis was used. Eight multiple linear regression analyses were carried out with SBP, DBP, HR, HRV (SDNN, HF, $\mathrm{LF} / \mathrm{HF}$ ), reaction time, and SRQ values at T2 as dependent variables, respectively. In each analysis, stimulus expectancies (told likelihood of caffeine intake), actual caffeine intake (0 $=$ no, $1=$ yes), habitual caffeine consumption, response expectancies (expected SRQ score), and the respective baseline (T1) value were used as independent (predictor) variables. Variables were entered in one step using the ENTER method.

To explore factors influencing subjective experience, a further analysis with T2 SRQ score as dependent variable was carried out. In the first step of this analysis, changes in 
autonomic variables between $\mathrm{T} 1$ and $\mathrm{T} 2(\triangle \mathrm{SBP}, \Delta \mathrm{HR})$, actual caffeine intake, and baseline SRQ score were entered. In the second step, stimulus and response expectancies, and somatosensory amplification score were stepped in the equation.

Table I. Descriptive statistics (means and SDs) of the assessed variables in the five groups

\begin{tabular}{|c|c|c|c|c|c|}
\hline & $\begin{array}{l}\text { Group } 1 \\
\text { (control) }\end{array}$ & $\begin{array}{c}\text { Group } 2 \\
\text { (conditional } \\
\text { placebo) }\end{array}$ & $\begin{array}{c}\text { Group } 3 \\
\text { (conditional } \\
\text { caffeine) }\end{array}$ & $\begin{array}{l}\text { Group } 4 \\
\text { (deceived } \\
\text { placebo) }\end{array}$ & $\begin{array}{l}\text { Group } 5 \\
\text { (caffeine) }\end{array}$ \\
\hline $\mathbf{N}$ & 22 & 18 & 20 & 22 & 25 \\
\hline $\begin{array}{l}\text { Habitual caffeine } \\
\text { consumption }\end{array}$ & $2.59 \pm 1.33$ & $2.83 \pm 1.65$ & $2.15 \pm 1.03$ & $3.36 \pm 1.46$ & $3.76 \pm 1.12$ \\
\hline Response expectancies & $27.13 \pm 6.69$ & $26.94 \pm 5.36$ & $26.70 \pm 5.23$ & $28.18 \pm 5.43$ & $31.04 \pm 5.20$ \\
\hline SSAS & $30.72 \pm 6.52$ & $28.38 \pm 7.57$ & $32.05 \pm 4.19$ & $29.72 \pm 5.98$ & $31.36 \pm 5.34$ \\
\hline $\mathrm{SBP}$ at $\mathrm{T} 1$ & $122.40 \pm 13.44$ & $113.77 \pm 10.46$ & $115.90 \pm 11.92$ & $124.59 \pm 11.32$ & $121.92 \pm 13.79$ \\
\hline SBP at T2 & $116.86 \pm 12.13$ & $114.72 \pm 9.91$ & $121.90 \pm 11.96$ & $123.05 \pm 10.29$ & $122.08 \pm 16.81$ \\
\hline $\mathrm{DBP}$ at $\mathrm{T} 1$ & $73.22 \pm 10.88$ & $70.61 \pm 7.66$ & $69.10 \pm 6.36$ & $74.04 \pm 9.90$ & $69.92 \pm 9.09$ \\
\hline $\mathrm{DBP}$ at $\mathrm{T} 2$ & $73.09 \pm 8.28$ & $70.05 \pm 7.01$ & $72.10 \pm 6.75$ & $73.85 \pm 9.94$ & $72.08 \pm 12.85$ \\
\hline $\mathrm{HR}$ at $\mathrm{T} 1$ & $77.05 \pm 14.11$ & $73.83 \pm 11.96$ & $73.90 \pm 10.09$ & $76.72 \pm 11.60$ & $79.16 \pm 13.77$ \\
\hline $\mathrm{HR}$ at $\mathrm{T} 2$ & $72.75 \pm 12.51$ & $69.22 \pm 7.49$ & $66.50 \pm 8.04$ & $74.54 \pm 15.47$ & $69.20 \pm 12.13$ \\
\hline HRV-SDNN at T1 & $213.05 \pm 25.46$ & $213.77 \pm 17.88$ & $213.20 \pm 14.70$ & $212.59 \pm 19.00$ & $208.75 \pm 20.07$ \\
\hline HRV-SDNN at T2 & $219.50 \pm 26.60$ & $220.27 \pm 12.65$ & $225.55 \pm 14.84$ & $216.68 \pm 17.60$ & $221.64 \pm 19.77$ \\
\hline HRV-HF at T1 & $24.15 \pm 7.37$ & $20.27 \pm 7.33$ & $22.55 \pm 6.96$ & $21.81 \pm 8.39$ & $22.25 \pm 7.18$ \\
\hline HRV-HF at T2 & $25.45 \pm 8.98$ & $20.22 \pm 6.55$ & $21.55 \pm 5.72$ & $23.86 \pm 11.84$ & $19.64 \pm 5.23$ \\
\hline HRV-LF/HF at T1 & $0.54 \pm 0.36$ & $0.50 \pm 0.44$ & $0.48 \pm 0.48$ & $0.45 \pm 0.37$ & $0.50 \pm 0.27$ \\
\hline HRV-LF/HF at T2 & $0.46 \pm 0.27$ & $0.38 \pm 0.36$ & $0.29 \pm 0.14$ & $0.47 \pm 0.29$ & $0.50 \pm 0.29$ \\
\hline RT at T1 & $352.70 \pm 43.57$ & $359.10 \pm 40.24$ & $350.94 \pm 29.94$ & $381.93 \pm 59.87$ & $361.41 \pm 57.40$ \\
\hline $\mathrm{RT}$ at $\mathrm{T} 2$ & $335.25 \pm 42.17$ & $326.05 \pm 24.35$ & $332.49 \pm 29.92$ & $358.03 \pm 51.58$ & $336.38 \pm 54.24$ \\
\hline SRQ at T1 & $13.63 \pm 4.91$ & $14.16 \pm 4.85$ & $14.90 \pm 4.33$ & $15.90 \pm 5.45$ & $11.84 \pm 3.54$ \\
\hline SRQ at T2 & $13.40 \pm 4.39$ & $14.33 \pm 5.73$ & $15.55 \pm 5.44$ & $15.68 \pm 4.62$ & $16.40 \pm 5.50$ \\
\hline
\end{tabular}

\section{Results}

Descriptive statistics of the assessed variables were presented in Table I, and results of the eight multiple regression analyses were presented in Table II. In summary, the equation was not significant in the case of LF/HF. Beyond respective baseline (T1) values, actual caffeine intake was a significant predictor of T2 values of SBP, HR (decrease), SDNN, and SRQ. Actual caffeine intake had no impact on values of DBP, HF, and RT at T2. Habitual caffeine consumption and stimulus expectancies (told likelihood of caffeine intake) did not influence any variables at $\mathrm{T} 2$. Response expectancy score (expected effects of caffeine) was a significant predictor of SRQ score at T2. It had no impact, however, on any objective variables.

As for the regression analysis exploring factors behind subjective experience, the impact of baseline SRQ score $(\beta=0.461 ; p<0.001)$ and actual caffeine intake $(\beta=0.272 ; p<0.01)$ was significant $\left(R^{2}=0.253\right)$ in the first equation. In the final equation, both of these variables remained significant $(\beta=0.477 ; p<0.001$, and $\beta=0.202 ; p<0.05$, respectively) and response expectancy score also reached the significance level $(\beta=0.264 ; p<0.01)\left(R^{2}=0.334\right)$. 
Table II. Results of multiple linear regression analyses

\begin{tabular}{|c|c|c|}
\hline Variable at $\mathrm{T} 2$ & Significant predictors & Not significant predictors \\
\hline $\operatorname{SBP}\left(R^{2}=0.471\right)$ & $\begin{array}{l}\text { SBP at T1 }(\beta=0.663 ; p<0.001) \\
\text { actual caffeine intake }(\beta=0.134 ; p<0.1)\end{array}$ & $\begin{array}{l}\text { habitual caffeine consumption } \\
\text { told likelihood of caffeine intake } \\
\text { expected subjective effects }\end{array}$ \\
\hline $\operatorname{DBP}\left(R^{2}=0.349\right)$ & $\mathrm{DBP}$ at $\mathrm{T} 1(\beta=0.602 ; p<0.001)$ & $\begin{array}{l}\text { actual caffeine intake } \\
\text { habitual caffeine consumption } \\
\text { told likelihood of caffeine intake } \\
\text { expected subjective effects }\end{array}$ \\
\hline $\operatorname{HR}\left(R^{2}=0.672\right)$ & $\begin{array}{l}\text { HR at T1 }(\beta=0.798 ; p<0.001) \\
\text { actual caffeine intake }(\beta=-0.210 ; p<0.001)\end{array}$ & $\begin{array}{l}\text { habitual caffeine consumption } \\
\text { told likelihood of caffeine intake } \\
\text { expected subjective effects }\end{array}$ \\
\hline $\operatorname{SDNN}\left(R^{2}=0.707\right)$ & $\begin{array}{l}\text { SDNN at T1 }(\beta=0.831 ; p<0.001) \\
\text { actual caffeine intake }(\beta=0.175 ; p<0.01)\end{array}$ & $\begin{array}{l}\text { habitual caffeine consumption } \\
\text { told likelihood of caffeine intake } \\
\text { expected subjective effects }\end{array}$ \\
\hline $\mathrm{HF}\left(R^{2}=0.119\right)$ & HF at T1 $(\beta=0.348 ; p<0.001)$ & $\begin{array}{l}\text { actual caffeine intake } \\
\text { habitual caffeine consumption } \\
\text { told likelihood of caffeine intake } \\
\text { expected subjective effects }\end{array}$ \\
\hline $\mathrm{LF} / \mathrm{HF}$ & - & $\begin{array}{l}\text { LF/HF at T1 } \\
\text { actual caffeine intake } \\
\text { habitual caffeine consumption } \\
\text { told likelihood of caffeine intake } \\
\text { expected subjective effects }\end{array}$ \\
\hline $\mathrm{RT}\left(R^{2}=0.673\right)$ & RT at T1 $(\beta=0.830 ; p<0.001)$ & $\begin{array}{l}\text { actual caffeine intake } \\
\text { habitual caffeine consumption } \\
\text { told likelihood of caffeine intake } \\
\text { expected subjective effects }\end{array}$ \\
\hline $\operatorname{SRQ}\left(R^{2}=0.338\right)$ & $\begin{array}{l}\text { SRQ at T1 }(\beta=0.489 ; p<0.001) \\
\text { expected subjective effects }(\beta=0.271 ; p<0.01) \\
\text { actual caffeine intake }(\beta=0.155 ; p<0.1)\end{array}$ & $\begin{array}{l}\text { habitual caffeine consumption } \\
\text { told likelihood of caffeine intake }\end{array}$ \\
\hline
\end{tabular}

\section{Discussion}

In a double-blind, placebo-controlled experiment with a natural history group, consumption of $5 \mathrm{mg} / \mathrm{kg}$ caffeine had an impact on participants' SBP, HRV-SDNN, HR (decrease), and subjective experience 40 minutes later even after controlling for respective baseline values, stimulus and response expectancies, and habitual caffeine consumption. No effects on DBP, HRV-HF, HRV-LF/HF, and reaction time were found. Stimulus expectancies (i.e. known chance of receiving caffeine) had no impact on any assessed variable. Beyond actual caffeine intake, response expectancy score was also a determinant of subjective experience which refers to a placebo component in the total effect. Actual autonomic (SBP, HR) changes and somatosensory amplification tendency, however, had no significant impact on subjective experience.

Intake of $5 \mathrm{mg} / \mathrm{kg}$ caffeine elevated participants' SBP, decreased their HR, and had not influenced DBP in the current study. As caffeine had an impact on HRV-SDNN which reflects all cyclic components responsible for HR variability and had no impact on the more specific 
$\mathrm{HF}$ and LF/HF indices, no conclusions can be drawn regarding the autonomic background of this change. Although the hypertensive effect of caffeine is generally accepted $(6,11,12,17$, $22,24,35)$, it was not demonstrated in all studies $(17,37)$. HR-related results are also mixed. While no changes following caffeine consumption were detected in some studies $(6,11,12$, $17,24,37)$, a significant decrease in HR was reported in others $(22,35,40,49)$. Reduction of HR possibly reflects a baroreceptor mediated response to pressor action (28). Caffeinerelated changes in various indices of HRV were investigated in several placebo-controlled studies with often contradictory results (no data from the caffeine-placebo literature is available, though). Increases in the HF component reflecting parasympathetic (vagal) activity were demonstrated in the majority of the studies $(16,27,33,50)$. No changes in SDNN, HF, and LF/HF were found in two studies $(31,48)$ and significant decreases were reported in a third paper (41). As for the LF/HF ratio, usually a significant increase has been reported which is attributed to the sympathetic activating effect of caffeine $(5,19,26)$. These contradictory results are usually explained by differences in experimental settings and participants' previous experiences with caffeine $(2,23)$.

Participants' reaction time was not influenced either by caffeine intake or by stimulus expectancies. This finding is in accordance with the results of previous studies $(24,35)$. In the study of Nash et al. (24), negative results were obtained following the intake of both $125 \mathrm{mg}$ and $325 \mathrm{mg}$ caffeine, and the latter dosage is comparable to that used in the recent study. According to these findings, caffeine may affect vigilance and psychomotor performance but has no direct impact on reaction time.

The only variable in the experiment that was influenced by response expectancies was the SRQ-score, i.e. caffeine related symptoms as experienced by the participants. Although actual caffeine consumption also impacted participants' subjective experience, according to the results of the last regression analysis, this effect could not be tracked down to peripheral autonomic changes (HR and SBP). Consequently, the moderating factor between subjective experience and caffeine intake may have been caffeine's central stimulating effect. Somatosensory amplification tendency did not prove to be a predictor of subjective state either, possibly because it refers to a tendency of amplifying aversive internal states and the SRQ consists of mainly positive items.

Changes in subjective variables are the most often mentioned effects of placebos, in both caffeine-related and medical research. A hypothesis proposed by Benedetti is that the most important mechanism behind objective (autonomic) changes caused by placebos is classical conditioning, while conscious expectations affect mainly subjective variables (4). Although this proposal cannot be regarded as a strict rule, it is in accordance with the majority of placebo-related findings and this is the case in the present study, too.

As for the role of conditional vs. deceptive administration, no significant impact on any outcome measure was found in the current experiment. This negative finding is in accordance with the results of other caffeine studies $(24,46,47)$, while differences between the effects of the two administration methods were found in pain-related clinical and experimental placebo studies $(30,43,44)$. According to these findings, results obtained from laboratory experiments using caffeine cannot be generalized to medical problems (i.e. external validity of caffeine studies seems to be quite low). Caffeine is mainly used by healthy individuals for recreational purposes and to improve cognitive abilities, and this context is clearly different from illnessrelated conditions. 


\section{Acknowledgements}

This research was supported by the Hungarian National Scientific Research Fund (OTKA K 109549) and by the János Bolyai Research Scholarship of the Hungarian Academy of Sciences (for F. Köteles).

\section{REFERENCES}

1. Arnaud MJ (2005): Caffeine. In: Encyclopedia of Human Nutrition, ed Caballero B, Elsevier, Oxford, pp. 247253

2. Attwood AS, Higgs S, Terry P: Differential responsiveness to caffeine and perceived effects of caffeine in moderate and high regular caffeine consumers. Psychopharmacology 190, 469-477 (2007)

3. Barsky AJ, Wyshak G, Klerman GL: The Somatosensory Amplification Scale and its relationship to hypochondriasis. J. Psy. Res. 24, 323-334 (1990)

4. Benedetti F (2008): Placebo Effects: Understanding the Mechanisms in Health and Disease. Oxford University Press, New York

5. Bonnet M, Tancer M, Uhde T, Yeragani VK: Effects of caffeine on heart rate and QT variability during sleep. Depress. Anxiety 22, 150-155 (2005)

6. Childs E, de Wit H: Subjective, behavioral, and physiological effects of acute caffeine in light, nondependent caffeine users. Psychopharmacology 185, 514-523 (2006)

7. Dawkins L, Shahzad F-Z, Ahmed SS, Edmonds CJ: Expectation of having consumed caffeine can improve performance and mood. Appetite 57, 597-600 (2011)

8. Elliman NA, Ash J, Green MW: Pre-existent expectancy effects in the relationship between caffeine and performance. Appetite 55, 355-358 (2010)

9. Fillmore MT, Mulvihill LE, Vogel-Sprott M: The expected drug and its expected effect interact to determine placebo responses to alcohol and caffeine. Psychopharmacology 115, 383-388 (1994)

10. Fillmore MT, Vogel-Sprott M: Psychomotor performance under alcohol and under caffeine: Expectancy and pharmacological effects. Exp. Clin. Psychopharmacol. 2, 319-327 (1994)

11. Flaten MA, Aasli O, Blumenthal TD: Expectations and placebo responses to caffeine-associated stimuli. Psychopharmacology 169, 198-204 (2003)

12. Flaten MA, Blumenthal TD: Caffeine-associated stimuli elicit conditioned responses: an experimental model of the placebo effect. Psychopharmacology 145, 105-112 (1999)

13. Glade MJ: Caffeine - Not just a stimulant. Nutrition 26, 932-938 (2010)

14. Harrell PT, Juliano LM: Caffeine expectancies influence the subjective and behavioral effects of caffeine. Psychopharmacology 207, 335-342 (2009)

15. Herz RS: Caffeine effects on mood and memory. Behav. Res. Ther. 37, 869-879 (1999)

16. Hibino G, Moritani T, Kawada T, Fushiki T: Caffeine enhances modulation of parasympathetic nerve activity in humans: quantification using power spectral analysis. J. Nutr. 127, 1422-1427 (1997)

17. Kirsch I, Rosadino MJ: Do double-blind studies with informed consent yield externally valid results? An empirical test. Psychopharmacology 110, 437-442 (1993)

18. Kirsch I, Weixel LJ: Double-blind versus deceptive administration of a placebo. Behav. Neurosci. 102, 319-323 (1988)

19. Kolodiřchuk EV, Arushanian EB: The effect of caffeine on the cardiac intervalogram indices depending on the ovarian cycle phase in women. Pharmacol. Toxsicol. 54, 28-30 (1991)

20. Köteles F, Gémes H, Papp G, Túróczi P, Pásztor A, Freyler A, Szemerszky R, Bárdos G: Validation of the hungarian version of the Somatosensory Amplification Scale (SSAS) (A Szomatoszenzoros Amplifikáció Skála (SSAS) magyar változatának validálása). Mentálhigiéné és Pszichoszomatika 10, 321-335 (2009)

21. Lotshaw SC, Bradley JR, Brooks LR: Illustrating caffeine's pharmacological and expectancy effects utilizing a balanced placebo design. J. Drug. Educ. 26, 13-24 (1996)

22. Mikalsen A, Bertelsen B, Flaten MA: Effects of caffeine, caffeine-associated stimuli, and caffeine-related information on physiological and psychological arousal. Psychopharmacology 157, 373-380 (2001)

23. Mort JR, Kruse HR: Timing of blood pressure measurement related to caffeine consumption. Ann. Pharmacother. 42, 105-110 (2008)

24. Nash JM, Holroyd KA, Rokicki LA, Kvaal S, Penzien DB: The influence of placebo awareness on stimulant drug response in a double-blind trial. Psychopharmacology 161, 213-221 (2002)

25. Nehlig A: Is caffeine a cognitive enhancer? J. Alzheimers Dis. 20, 85-94 (2010)

Acta Physiologica Hungarica 102, 2015 
26. Nishijima Y, Ikeda T, Takamatsu M, Kiso Y, Shibata H, Fushiki T, Moritani T: Influence of caffeine ingestion on autonomic nervous activity during endurance exercise in humans. Eur. J. Appl. Physiol. 87, 475-480 (2002)

27. Notarius CF, Floras JS: Caffeine enhances heart rate variability in middle-aged healthy, but not heart failure subjects. Journal of Caffeine Res. 2, 77-82 (2012)

28. Nurminen ML, Niittynen L, Korpela R, Vapaatalo H: Coffee, caffeine and blood pressure: a critical review. Eur. J. Clin. Nutr. 53, 831-839 (1999)

29. Oei A, Hartley LR: The effects of caffeine and expectancy on attention and memory. Hum. Psychopharmacol. 20, 193-202 (2005)

30. Pollo A, Amanzio M, Arslanian A, Casadio C, Maggi G, Benedetti F: Response expectancies in placebo analgesia and their clinical relevance. Pain 93, 77-84 (2001)

31. Rauh R, Burkert M, Siepmann M, Mueck-Weymann M: Acute effects of caffeine on heart rate variability in habitual caffeine consumers. Clin. Physiol. Funct. Imaging 26, 163-166 (2006)

32. Ribeiro JA, Sebastião AM: Caffeine and adenosine. J. Alzheimers Dis. 20, 3-15 (2010)

33. Richardson T, Rozkovec A, Thomas P, Ryder J, Meckes C, Kerr D: Influence of caffeine on heart rate variability in patients with long-standing type 1 diabetes. Diabetes Care 27, 1127-1131 (2004)

34. Rush CR, Sullivan JT, Griffiths RR: Intravenous caffeine in stimulant drug abusers: subjective reports and physiological effects. J. Pharmacol. Exp. Ther. 273, 351-358 (1995)

35. Schneider R, Grüner M, Heiland A, Keller M, Kujanová Z, Peper M, Riegl M, Schmidt S, Volz P, Walach H: Effects of expectation and caffeine on arousal, well-being, and reaction time. Int. J. Behav. Med. 13, 330-339 (2006)

36. Schneider R (2008): Unspecific effects of caffeine consumption: when does the mind overrule the body? In: Caffeine and Health Research, ed Chambers KP, Nova Science Publishers, New York, pp. 143-160

37. Smith A, Whitney H, Thomas M, Perry K, Brockman P: Effects of caffeine and noise on mood, performance and cardiovascular functioning. Hum. Psychopharmacol. Clin. Exp. 12, 27-33 (1997)

38. Smith A: Effects of caffeine on human behavior. Food Chem. Toxicol. 40, 1243-1255 (2002)

39. Smith A (2005): Caffeine. In: Nutritional Neuroscience, eds Lieberman HR, Kanarek RB, Prasad C, CRC Press, FL, pp. 335-359

40. Smits P, Schouten J, Thien T: Cardiovascular effects of two xanthines and the relation to adenosine antagonism. Clin. Pharmacol. Ther. 45, 593-599 (1989)

41. Sondermeijer HP, van Marle AGJ, Kamen P, Krum H: Acute effects of caffeine on heart rate variability. Am. J. Cardiol. 90, 906-907 (2002)

42. Sun Y, Zhang Y, He N, Liu X, Miao D: Caffeine and placebo expectation: Effects on vigilance, cognitive performance, heart rate, and blood pressure during 28 hours of sleep deprivation. Journal of Psychophysiol. 21, 91-99 (2007)

43. Vase L, Robinson ME, Verne GN, Price DD: The contributions of suggestion, desire, and expectation to placebo effects in irritable bowel syndrome patients. An empirical investigation. Pain 105, 17-25 (2003)

44. Verne GN, Robinson ME, Vase L, Price DD: Reversal of visceral and cutaneous hyperalgesia by local rectal anesthesia in irritable bowel syndrome (IBS) patients. Pain 105, 223-230 (2003)

45. Vogel-Sprott M, Fillmore MT (1999): Expectancy and behavioral effects of socially used drugs. In: How Expectancies Shape Experience, ed Kirsch I, American Psychological Association, Washington, DC, pp. 215232

46. Walach H, Schimdt S, Bihr Y-M, Wiesch S: The effects of a caffeine placebo and experimenter expectation on blood pressure, heart rate, well-being, and cognitive performance. European Psychologist 6, 15-25 (2001)

47. Walach H, Schmidt S, Dirhold T, Nosch S: The effects of a caffeine placebo and suggestion on blood pressure, heart rate, well-being and cognitive performance. Int. J. Psychophysiol. 43, 247-260 (2002)

48. Waring WS, Goudsmit J, Marwick J, Webb DJ, Maxwell SRJ: Acute caffeine intake influences central more than peripheral blood pressure in young adults. Am. J. Hypertens. 16, 919-924 (2003)

49. Whitsett TL, Manion CV, Christensen HD: Cardiovascular effects of coffee and caffeine. Am. J. Cardiol. 53, 918-922 (1984)

50. Yeragani VK, Krishnan S, Engels HJ, Gretebeck R: Effects of caffeine on linear and nonlinear measures of heart rate variability before and after exercise. Depress. Anxiety 21, 130-134 (2005) 